\title{
Discurso e imagem: a representação do trabalho nas capas do Manifesto Comunista*
}

\author{
Angela Maria Rubel Fanini \\ Universidade Tecnológica Federal do Paraná
}

Neste artigo, analisam-se seis capas de diferentes edições da obra Manifesto Comunista de Karl Marx e Friedrich Engels, verificando como o projeto gráfico representa o âmbito do trabalho e a luta dos trabalhadores, considerando-se que a obra elaborouse para o trabalhador instado a lutar. O universo do trabalho é representado articulado à luta; impessoalizado, com ênfase na produção e pessoalizado, destacando-se a figura do trabalhador ora ativo, ora passivo. As novas tecnologias de produção da era industrial, o espaço da rua e da família estão presentes.

Palavras-chave: Literatura comunista - Projeto gráfico - Discurso - Imagem do trabalho - Imagens da tecnologia
In this paper six covers of the book Communist manifesto by Karl Marx and Friedrich Engels from different editions were analysed to verify how the graphic project depicts the labour universe and workers' struggle, considering that the book is mainly addressed to workers who are exhorted to fight. The labour universe is represented by the articulation of fight strategies; depersonalized, focusing on production field, personalized, aiming at worker's pictures in active and passive attitudes. New technologies employed in the industrial era, street and family scenarios are present as well.

Keywords: Communist literature Graphic design - Discourse - Labour images - Technology images

\section{O universo do trabalho e outros sentidos: a luta, a transformação e a ontologia}

Jeste artigo, analisou-se a representação imagística do universo do trabalho em 1 seis capas de diferentes edições da obra Manifesto Comunista de autoria de Karl Marx (1818-1883) e Friedrich Engels (1820-1895). O interesse pelo universo do trabalho e sua representação vincula-se à linha de pesquisa Trabalho e Cultura, focalizando diversas formas de aparição do trabalhador nos bens culturais.

"Discourse and image: representation of labor universe on the covers of Communist Manifesto

' Endereço para correspondências: Rua Ana Berta Roskamp, 1020, sobrado 01, Jardim das Américas, Curitiba/PR, 81530-250 (rubel@utfpr.edu.br).

${ }^{2}$ Esse autor (1980), seguindo o marco marxista, também trata o trabalho como categoria fundante do ser social, entendendo a humanização e a socialização do homem como resultado das relaç̃̃es de trabalho. 
Tendo por base, teóricos que destacam o universo do trabalho como categoria ontológica do ser social, Marx (1986), Engels (1990), Lukács² (18851971) e Antunes (2002), procura-se entender como os intelectuais, sobretudo os responsáveis pelo projeto gráfico das capas de livros, representam o trabalho em discursos imagísticos.

A escolha da obra se dá pela evidência de seu conteúdo, vinculada ao mundo do trabalho em articulação e em confronto com o mundo do capital. A composição discursiva da obra não é apenas descritiva, mas utiliza-se de linguagem argumentativa e persuasiva, visando intervir na realidade. Para Marx e Engels, pensadores da filosofia da práxis revolucionária, o discurso é uma forma de intervenção ${ }^{3}$ social. Em Manifesto comunista, constrói-se um discurso sobre as condições da vida econômica do século XVIII e XIX, enfocando as contradições entre trabalho e capital, instando os trabalhadores a revolucionarem as condições de existência materiais e sociais. $\mathrm{O}$ discurso analisa a realidade concreta fora do discurso, a partir do método dialético-histórico em que o concreto vivido se transforma em concreto pensado, voltando-se para a realidade a fim de transformá-la e se dirige ao trabalhador, conclamando-o a agir.

O estudo se justifica uma vez que a obra ainda é lida haja vista as numerosas edições recentes em âmbito nacional e internacional. Outra questão que justifica a análise sobre o trabalho se vincula à contemporaneidade em que as práticas laborais, embora modificadas pela nova etapa do capitalismo tardio $^{4}$, ainda são preocupantes e enfrentam dificuldades e desafios. $O$ mundo do trabalho apresenta relevância uma vez que as condições de expropriação de grande parte do conjunto de trabalhadores ainda persistem e tem se intensificado. Agravando esse quadro, vários pensadores da contemporaneidade, como Gorender (1999), Gorz (2003) e Bauman (2008), destacam que o exercício da cidadania tem-se enfraquecido, sofrendo um processo constante de substituição pela atividade unidimensional do consumo. O cidadão, instaurado sobretudo com a modernidade, vê-se subsumido ${ }^{5}$ pelo consumidor. Nesse cenário, o trabalho vai perdendo a capacidade de socialização, de formação ontológica do ser social,

\footnotetext{
${ }^{3}$ Para esses pensadores, o terreno das idéias parte do concreto e a ele deve retornar no sentido de alterar a realidade, distanciando-se de uma pespectiva descritiva ou apenas interpretativa dos fatos. Exemplifica-se explicitamente essa postura política na seguinte exortação "Os filósofos se limitaram a interpretar o mundo de diferentes maneiras; o que importa é transformá-lo" (MARX, 1986; p. 14).

" Toma-se o termo da obra de Jameson (2001) em que se afirma a permanência do sistema capitalista na atualidade, sobretudo a versão neoliberal americana, e suas articulações com um determinado universo simbólico e das idéias que visa reforçar aquele modo de produção. Enfatiza a força do âmbito econômico, seguindo Marx, e suas articulações com o universo cultural e político. $\mathrm{Na}$ perspectiva do trabalhador, destaca a necessidade de se fortalecer "a coletividade social", como questão de base para qualquer reação política progressista e inovadora no enfrentamento ao capital e à globalização (p. 156).

${ }^{5}$ Destaca-se, no entanto, seguindo Jameson (2001), que esse imperialismo cultural do consumo é uma outra dimensão da gobalização econômica. Objetiva-se obliterar o processo do trabalho que produz os artefatos e bens, focando-se na "livre" circulação e consumo (p. 143).
} 
de dignitïcação do humem. reduzindo-se a um instrumental para inserir o indivídun cada vez mais na suciedade de consumo. A partir de una perspectiva crítica e emancipatória, urge se refletir sobre as condiçōes ontológicas do trabalho, buscando resgatar na atividade laboral outros sentidos que não o estreitamente instrumental e de simples mediação para a ạuisição de bens, contra * pondo-sc à lógica capitalista da obsolescênciáa programada. Entender como ocorre a representação do mundo do trabatho. procurando-se encontrar esses outros sentidos vollados para a luta, o coletivo, a emancipação, a crítica ao capital é uma contribuição necessária. A pesquisa visa tambéın articular as áreas de Commicação e Educação. demonstrando que a linguagem imagísticaı é intportante fonte de conhecimento. Verificar sob quais perspectivas o intelectual do trabalho imaterial (projeto gráfico) representa o nundo do traballos material e do trabalhador pode desvendar as construçōes simbólicas desse universo e propriciar a rcflexão docente e discente sobre essas lormulaçòes. A hislória dos que produzem a riquicza e os bens de consumo material muitas vezes é pouco estudada, valorizanjdo-se a história da política, das idéias, da demografia, uos latos históricos consagrados. Avivar essa história, a partir do universo sisnbólico, é um dos caminhos para uma prática docente que precenda dar visilbilidade àqueles que proubzem a riqueza matcrial, mas que nem sempre dela usutimem.

\section{$\Lambda \mathbf{s}$ imagens do trabalho e a conexão com o discurso}

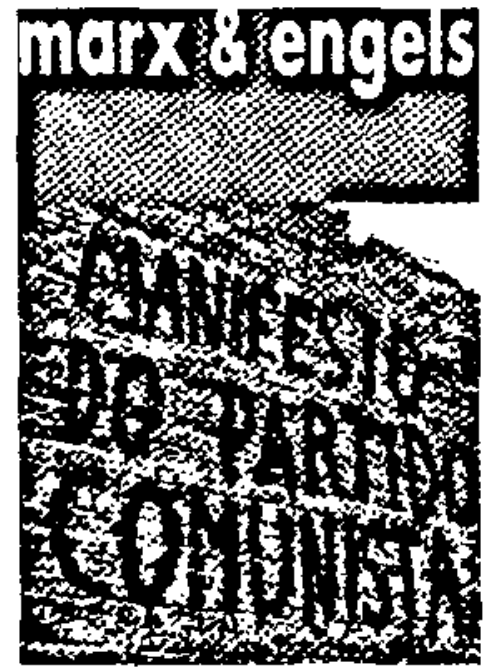

Figura 1

Marx,K. \& ENGELS, F. Manifesto do partido commista. São Paulo: Escriba. 1968. 
Nessa capa, a autoria ocorre no topo, em fonte de cor branca, sobre fundo em cor vermelha, elemento vinculado culturalmente ao Comunismo. O mundo do trabalho material é representado na parede de tijolos aparentes, tendo-se o foco na produção coletiva e não no sujeito individualizado, vinculando-se à idéia central da obra em que a força da luta advém da coletividade. O trabalho material, representado por sólida parede de tijolos aparentes, é pano de fundo para a inscrição do título da obra em cor preta. Além de representar o trabalho coletivo e em construção, dá sustentação para o terreno das idéias em que se reforça o discurso voltado para a ação do trabalhador, ou seja, a enunciação de um manifesto. A seleção das imagens que associam as idéias e a práxis comunica que há uma articulação entre produção e educação política do trabalhador. O título da obra ocorre em grafite, cor preta e em fonte de característica artesanal, sinalizando para a estratégia de pichação, remetendo à atitude marginal, provavelmente, de enfrentamento à censura exercida pelo regime ditatoral visto que a publicação da edição se dá em pleno Segundo Golpe Militar. A imagem da pichação se evidencia, ocultando o sujeito da ação, protegendo-o e mantendo-o na clandestinidade, mas simultaneamente revela a existência de práticas revolucionárias clandestinas de onde emerge esse sujeito.

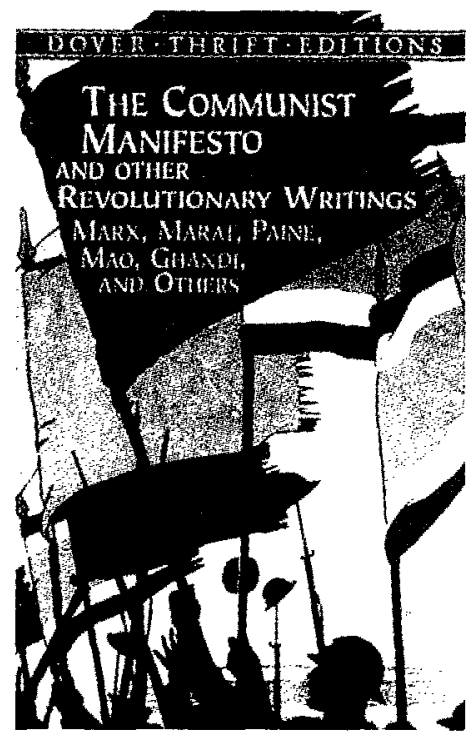

Figura 2

Marx, K. et al., The Communist Manifesto and other revolutionary writings. New York: Dover Thrift Edition, 2003.

Essa obra constitui uma antologia de discursos de líderes revolucionários (Marx, Engels, Lenin, Trotsky, Marat, Danton, Mohandas Gandhi, Mao Tse-tung e outros). 
Na capa, o destaque, no entanto, vai para o Manifesto comunista. Há ênfase para a figura do trabalhador em atitude de luta. O trabalho é figurado sobretudo na primeira imagem apresentada na cor preta em que a figura do trabalhador se reconhece pelo uso do capacete que também remete a imagens de soldados da II Guerra Mundial. Nas figuras subsequentes, em plano secundário à primeira, os capacetes estão pendurados sobre os canos de armas de fogo, propiciando a idéia de confronto com o capital. Essa remissão ao período da guerra causa certa estranheza visto que o foco desse conflito se deu, em grande parte, a disputas nacionalistas, contrariando, assim, o caráter internacionalista da obra em tela que se dirige aos proletários, independente de nacionalidade. Esse estranhamento se dissipa parcialmente à medida que os trabalhadores seguram bandeiras de variadas cores (vermelha, azul, amarela, bicolor e tricolor) que podem simbolizar a união do operariado de várias nações contra um inimigo comum, ou seja, o capital. A imagem do coletivo de trabalhadores em atitude de luta é coerente com a obra, mas essa recuperação de certa imagística bélica entra em dissonância com o período da edição em que há um enfraquecimento do movimento operário no Ocidente. A partir, mormente de 1980, ocorrem profundas alterações no mundo do trabalho, desencorajando as lutas operárias. A revolução da micro eletrônica gera uma mudança no processo produtivo, automatizando-o e desempregando; boa parte da gestão passa do modelo taylorista-fordista para o toyotismo, exigindo mais qualificação do trabalhador (consequentamente aumenta a taxa de desemprego) e a consolidação das tecnologias de comunicação beneficiam o movimento fluido e rápido das operações financeiras globalizadas do capital, prejudicando o capital produtivo nacional. Além disso, como Sennet (2009) assevera, o capital móvel em busca de trabalhadores menos politizados também neutraliza a possibilidade da luta operária, "corroendo o caráter" uma vez que o trabalhador também se move de um emprego a outro, nada mais tendo de fixo que lhe possibilite construir uma narrativa coerente em que se reconheça e aos outros. Nesse passo, o conjunto de imagens causa estranheza visto o desajuste com o contexto sócio-econômico. Entretanto, a linguagem simbólica imagística não só "reflete" o real, mas o "refrata", revelando que o projeto gráfico pode apresentar uma intencionalidade. A recuperação da imagética de luta da II Guerra Mundial pode sinalizar uma intenção de escovar a "história a contrapelo", fazendo surgir daí a história dos vencidos como um alerta benjaminiano em que os escombros da história contam uma outra narrativa a ser reativada, mesmo e principalmente,

\footnotetext{
${ }^{6}$ Tomam-se os termos refratar e refletir dos filósofos da linguagem Bakhtin e Volochinov (1986) cuja teoria materialista da linguagem possibita entender não só discurso verbal, mas também o imagético, articulado à realidade, refletindo-a e simultaneamente refratando-a. Não é cópia fiel da realidade visto se formalizar a partir de um certo ponto de vista histórico e ideológico sobre o mundo, representando-o segundo mirantes e objetivos diversos.
} 
em um momento pouco propício ao movimento dos trabalhadores. A contraposição do campo simbólico das imagens com o histórico causa estranheza, mas leva a uma percepção menos automatizada, abrindo outras possibilidades políticas e de reflexão, gerando uma leitura da obra mais crítica e voltada para a práxis.

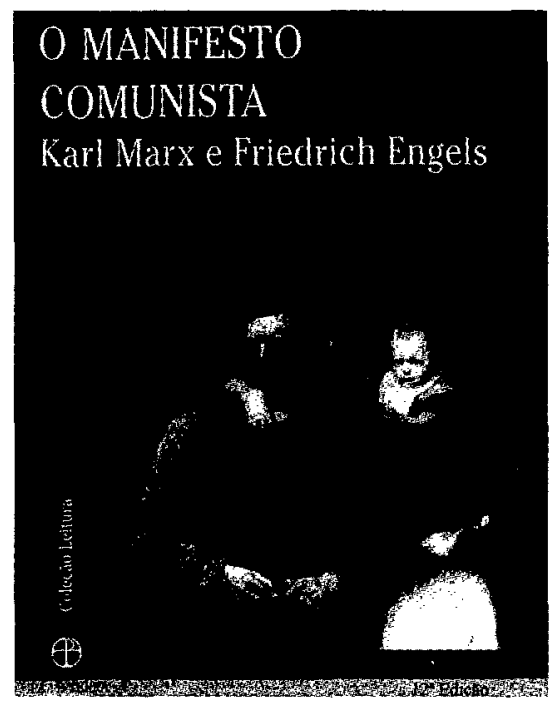

Figura 3

Marx, K. \& ENGELS, F. O Manifesto Comunista. 12a Edição. São Paulo: Paz e Terra, 2003.

Nessa capa, tem-se a predominância da cor preta, construindo um cenário em que se reforça a imagem da família do trabalhador em atitude de desolação. $\mathrm{O}$ trabalhador masculino posta-se à frente, apresentando um olhar preocupado e apreensivo. As mãos responsáveis pela execução do trabalho sobressaem, mas estão inativas. $\mathrm{O}$ elemento feminino apresenta comportamento desolado, retratado amparando e sendo amparado, destacando-se a solidariedade da família operária, mas os olhares e a postura corporal são de desilusão. Novamente a parede de tijolos à vista por trás das personagens simboliza o universo do trabalho material. Entretanto aqui, diferentemente da primeira capa, sinaliza para a rusticidade e pobreza da moradia. A imagem destaca a família e não o coletivo dos trabalhadores, em desacordo com o conteúdo da obra. Em oposição à capa anterior, a imagem desolada parece reforçar o momento histórico da edição em que o capital móvel, volátil, fluido e de gestão toyotista e automatizado tem gerado o desemprego estrutural, a parcelização e a precarização do mundo do trabalho, desalojando trabalhadores de seus postos. O semblante das personagens aparenta também uma expressão difusa de medo. $O$ sujeito contemporâneo, segundo Bauman (2008), vivencia o medo líquido, sobretudo, 
o trabalhador. desocupado. pelas já citadas alteraçôes tecnológicas e de gestão do capital que o alijam de paradigunas sólidos como o emprego fixxo nas grandes plantas fahris que the dava uma certa estabilidade. inclusive para lutar no coletivo por melhores condiçōes de trabalho. Bauman rccupera a idćia de denıcracia gregil em yue o cidadão, no s'spaço coletivo da ágora, debate sobre os rumos da pólis. Pura esse autor. o empobrecimento do coletivo também é catraclerística da atualidade cm que al "suciedade individualizada" sonnente acome à ágora para se apropriar do social palä henefício privado. A Jinguagem inlugíslica evidencia essa almostera de medo, de isolamento do social, de auséncia de luta. As imagens selecionadas se inserem dentro de uma rellexão contemporîtnea maior eın cjue autores como Bauman, Sennet e Jameson problemiltizam o processo de esvaziantento do coletivo, propiciando uma possível toniada de consciència sobre a importáncia da ágora para a vistialização de outra sociedade. Nessa capa, a luz incide em maior glau na ligura do infante cujo vestimenta E majoritariantente de cor vermelha, remelendo ao movimento comunista. A luminosidade parece sinalizar o poder do lituro na imagem da criança. A companheira recebe luz na parte interior de suas vestes (cor brancit) e o trabalhador masculino, un cuja vestimenta predomina o preto e o marrom. é a lïgura menos contetmplada pela luminosidilủe. cnfatizando-se assim a sua descentralidide. As imagens tem um poder heurístico cyue pode ser cxplorado cucmedo da leitura da obra em tela, Ievando o leitor a repcnsar paradigmas.

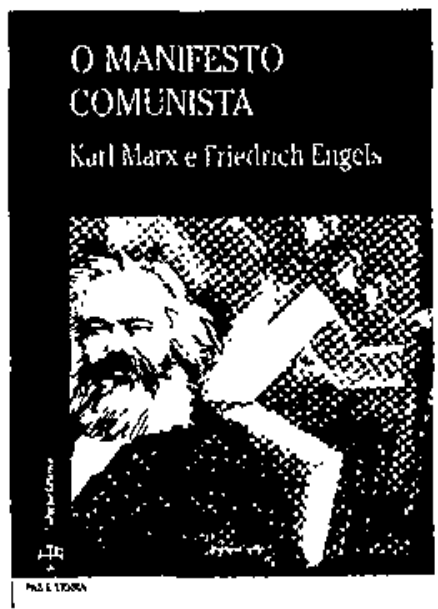

Figura 4

Marx, K. \& ENGElS, F. O Manifesto Crmminta. 12a Edição. São Paulo: Paz e Terra, 20()4.

Nessal capa, tem-se em primeiro plano, à esguterdà, a figura de um dos autores, cridencianuó-sc apenas Karl Marx (lace, cabelos e barba em cor branca e vestimenta preta). O mundo do trabalho comparece, mas como pano de fistolo. 
O trabalho assume características humanas estilizaldas, sendo representado por figuras masculinas em cor vermelha. A primeira figura destaca-se em posiçào de ataque, seguida por outras que reproduzem a primeira ent semclhante attitukle e simnlando uma postura coletiva de enlrentamento. O espírito da obra ent que o trabalhador colctivo, como sujeito revolucionútio, é chamado à luta contra o uıpital, está asssegurado pelo conjunto inagístico. () período da edição evidencia a conergència de novas formas do capital associado a tecnologias avançadas de automação, inlluenciando na elaboração de uma inagética macuinistica do trabalhador. Essa estilizaçäo que aproxima a figura do Irabalhadisr à do robô e da máyuina, amplia simbolicimante o poder físico do trabalhador, cuja atitude belicosa garunte o embate. Aqui a tecnologia que, não raras iezes, tem desenpregado. sendo por muitos "demonizada", é visualizada em umil perspectiva emancipatória, ilterando a imagística do trabalhador. Seguindo Feenberư (2002), avesso a uma perspectiva deteminista, instrumental ou pessimista da lecnologia, esta pode ser constiturda para o benefício da sociedade se for problematizada c constituída a partir de uma radicalizaçuīo democrática em çue atuem os vários sijeitos sociais. O conjunto de imagens leva a relletir sobre a tecnologia como elemento constituinte dos trabalhadores c, ao mesmo tempo, scndo usada por eles na construção de outro projeto social, com possibilidade de se alterar as condiçōes de produçĩo e de Iuta.

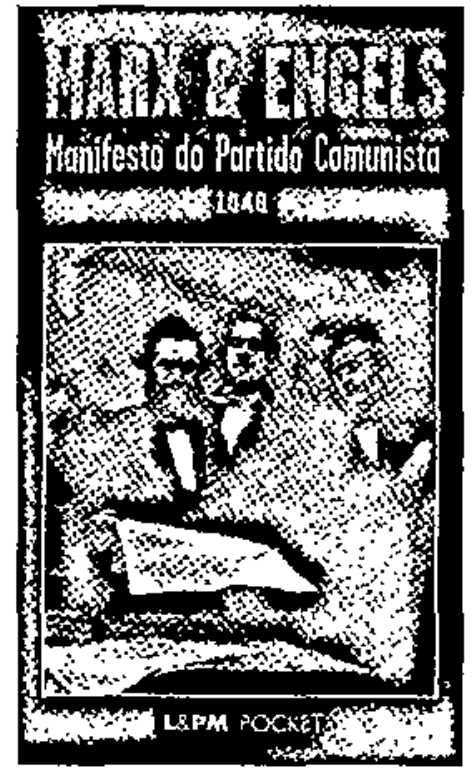

Figura 5

Marx, K. \& ENGELS. F. Mamfesto do Partido Commista (1848). Porto Alegre: L\&PM Pocket, 2002. 
Nessa capa, foi escolhida a reprodução da tela Marx e Engels na redação da Nouvelle Gazette Rhénane (Museu de Marx e Engels em Moscou) onde Marx trabalhou como chefe de redação. O trabalho imaterial e simbólico recebe ênfase na imagem figurativa dos intelectuais. Pode-se pressupor que o texto do Manifesto está sendo lido e analisado pelos autores, antes de ser exposto ao destinatário. A teoria, a produção imaterial, sendo elaborada, não por apenas um sujeito isolado, mas em diálogo e confronto com outros sujeitos. O saber revolucionário está em destaque, demonstrando sua importância para a práxis comunista, inexistente sem a teoria. O produto imaterial, refletindo sobre as condições de trabalho material, é motivo de representação imagística, conectando-se à obra. A imagística também aponta para o enfraquecimento do movimento operário e o afastamento parcial dos intelectuais em relação às manifestações coletivas de rua. Segundo Anderson (1989), o Marxismo, especialmente no Ocidente, e após o advento do regimes totalitários soviético, alemão e italiano, passa a se constituir como um discurso muito confinado aos ambientes universitários, afastando-se em grande medida das ruas e dos trabalhadores. Há um declínio, inclusive, de temas políticos e econômicos voltados para a ação e uma predominância de temas culturais, filosóficos e estéticos nas obras de grandes pensadores marxistas a partir desse momento. A capa se conecta a essa versão da trajetória do marxismo em que há um afastamento da política e um enclausuramento dentro da academia. Nessa perspectiva, podese problematizar por intermédio da linguagem imagística os caminhos e desacaminhos que articulam ou não a educação e a ação. Os nomes dos autores ocorrem na cor vermelha e o título da obra e a data da primeira publicação em cor amarela, sob fundo preto. Nas vestimentas das figuras humanas, predomina o preto e o cinza e, no cenário, o rosa claro e o preto. A luz incide, majoritariamente, sobre as folhas de papel em que se apresenta o trabalho imaterial, destacando-o e reforçando-o.

$\mathrm{Na}$ capa a seguir, há destaque para as caricaturas dos autores. As cores fogem ao estereótipo do vermelho, sendo variações de branco, preto e cinza, indicando a técnica da xilogravura, vinculada à impressão do cordel. $O$ trabalho é representado sem o sujeito explícito da produção. Tem-se os dois principais meios de circulação da produção do século XIX, o navio e o trem a vapor, destacando a questão da tecnologia e progresso técnico a acompanhar o movimento do capital e do trabalho. A representação do progresso tecnológico entra em consonância com a obra haja vista que os autores valorizam as conquistas da era industrial e da maquinaria. Para eles, urge adaptálas a novos desígnios para o bem dos trabalhadores e não de uma minoria que detém a propriedade dos meios. Também como menção ao trabalho, figura o símbolo do comunismo soviético, em que sobressaem dois meios de produção, a foice e o martelo, ambos vinculados ao trabalho material e à mão do trabalhador. 
Traz a informação de que o texto não é original, mas uma decodificação para a narrativa de cordel, dentro de uma visão atual de inclusão social cidadã. A ênfase no meios de transporte vincula-se ao momento atual em que a circulação de bens é maior em virtude dos meios de transporte serem mais avançados, como se evidencia em parte da sociedade globalizada. Entretanto, o destaque para a circulação de bens empobrece a pespectiva da produção, pois oblitera-se a imagem daquele que produz e como produz, reforçando a fetichização da mercadoria.
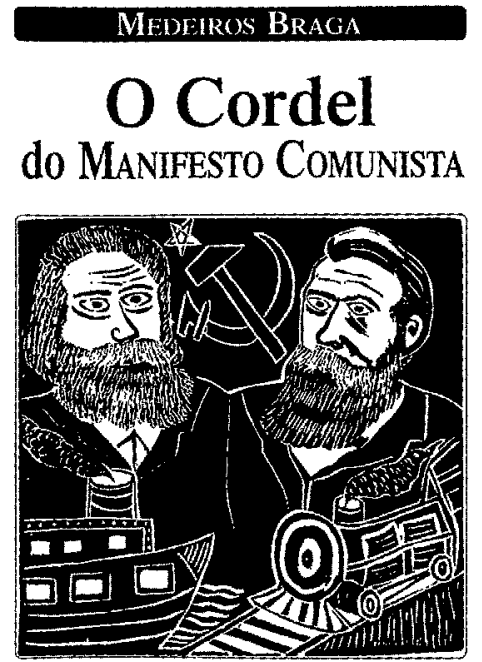

$2^{*}$ edictio revista e aumentada

A

EDIORA ALFA-OMEgA

Figura 6

BRAGA, M. O Cordel do Manifesto Comunista. São Paulo: AlfaÔmega, 2008.

\section{Considerações finais}

O estudo se concentrou nas capas, em número de seis, em que ocorrem imagens do trabalho, da tecnologia da era industrial, do trabalhador coletivo, na família ou na rua. Verificou-se que o conteúdo da obra está representado, na maioria das vezes, em consonância com o propósito dos autores. Na obra em tela, o vocábulo "luta" aparece vinte e seis vezes, sendo retomado e ampliado por vocábulos semanticamente próximos como "destruição", "revolução", "aniquilar", "empunhar armas", "conflitos", "processo de dissolução", "estilhaçar", "suprimir pela violência", "revolução proletária", "revolução comunista". Esse uso vocabular está associado ao trabalhador e tido como sujeito coletivo da transformação social, 
comprovando-se que o discurso é voltado para o embate, sendo que as imagens do trabalhador em posição de luta estão em sintonia com a obra. A cor vermelha e o símbolo do Comunismo Soviético figuram em parte das capas, reproduzindo signos culturais referentes à esquerda. A figura feminina proletária comparece, demonstrando afinidade com a obra que trata do operariado feminino. As novas tecnologias da era industrial são apresentadas, vinculando-se à obra que trata das condições de produção e sua modificação. $\mathrm{O}$ trabalho imaterial dos intelectuais comprometidos com a causa operária está representado, reforçando o discurso da práxis revolucionária. Por outro lado, o momento de edição das obras interfere na imagística, evidenciando-se o esvaziamento da coletivo, o desemprego estrutural, a apatia do movimento operário e a ênfase no mundo das idéias marxistas dissociado da práxis. Ler um clássico a partir de sua representação imagística contribui para repensar por que motivos é reeditado e como as condições objetivas em que foi escrito entram em consonância e dissonância com momentos históricos posteriores, ampliando a discussão entre comunicação imagística e educação.

\section{Referências bibliográfica}

ANDERSON, P. Considerações sobre o Marxismo Ocidental. Trad. Marcelo Levv. São Paulo: Brasiliense, 1989.

ANTUNES, R. Os sentidos do trabalho: ensaio sobre a afirmação e a nega-

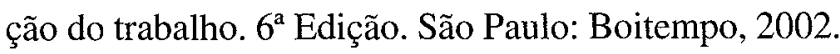

BAKHTIN, M. \& VOLOCHINOV, V.N. Marxismo e Filosofia da linguagem. Trad. Michel Lahud e Yara Frateschi Vieira. São Paulo: Hucitec, 1986.

BRAGA, M. O Cordel do Manifesto Comunista. São Paulo: Alfa-Ômega, 2008.

BAUMAN, Z. A sociedade individualizada: vidas contadas e histórias vividas.Trad. José Gradel. Rio de Janeiro: Zahar, 2008.

ENGELS, F. O papel do trabalho na transformação do macaco em ho-

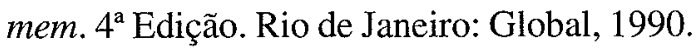

GORENDER, J. Marxismo sem utopia.São Paulo: Ática, 1999.

GORZ, A. Metamorfoses do trabalho. São Paulo: Annablume, 2003.

KARL, M. A ideologia alemã (Feuerbach).Trad. José Carlos Bruni e Marco

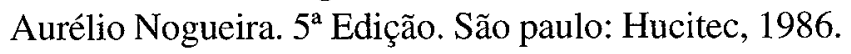

KARL, M. \& ENGELS, F. Manifesto do partido comunista. São Paulo: Escriba, 1968. 
KARL, M. \& ENGELS, F. O Manifesto Comunista. $12^{a}$ Edição. São Paulo: Paz e Terra, 2003.

KARL, M. \& ENGELS, F. $O$ Manifesto Comunista. $12^{a}$ Edição. São Paulo: Paz e Terra, 2004.

KARL, M. \& ENGELS, F. Manifesto do Partido Comunista (1848). Porto Alegre: L\&PM Pocket, 2002.

KARL, M. et al. The Communist Manifesto and other revolutionary writings. New York: Dover Thrift Edition, 2003.

FEENBERG, A. Transforming Technology. Oxford: Oxford University Press, 2002.

JAMESON, F. Pós-Modernismo - a lógica cultural do capitalismo tardio. São Paulo: Ática, 1997.

LUKÁCS, G. The ontology of social being: Labour. Londres: Merlin Press, 1980.

SENNET, R. A corrosão do caráter: consequências pessoais do trabalho no novo capitalismo. Trad. Marcos Santarrita. Rio de Janeiro: Record, 2009. 